\title{
Clausewitz y la teoría de las relaciones internacionales
}

\section{Clausewitz and the theory of internacional relations}

\author{
Pablo Anzaldi*
}

A la memoria de Claudia Castañeda Navarrete

\section{Resumen}

El presente artículo analiza las fuentes, la estructura y los significados posibles del pensamiento de Clausewitz. Propone una interpretación de Vom Kriege en sintonía con el pensamiento de Goethe y Fichte. Señala que Clausewitz construyó los cimientos de una teoría de la política integral, reintroduciendo la naturaleza humana frente a las convenciones. Configurando un orden conceptual clásico dominante sobre ciertos aspectos románticos, Clausewitz forjó conceptos fundamentales para la crítica de la visión liberal de la política.

Palabras Clave: Clausewitz, política, naturaleza humana, cultura.

\section{Abstract}

This article examines the sources, structures and the possible meaning of Clausewitz's theory. The paper suggests an interpretation of Vom Kriege and provides a comparison with Goethe and Fichte. It points out that

Director, área de Política Internacional, IPEC, Universidad Católica de La Plata <pabloanzaldi@gmail.com>.

Recibido el 3 de agosto de 2009; aceptado el 19 de octubre de 2009. 
Clausewitz set the rationale of an integral politics theory, reintroducing human nature as opposed to culture and creating a classical conceptual order prevailing over Romanticism, as well as forging essential concepts for a critical view of liberalism.

KeY Words: Clausewitz, politics, human nature, culture. 


\section{INTRODUCCIÓN}

La división entre ciencias sociales, disciplinas humanísticas y doctrinas militares ha relegado a Carl von Clausewitz a un lugar incómodo, a medio camino entre la filosofía, la ciencia política, las relaciones internacionales y la estrategia militar. Un texto como Vom Kriege $^{1}$ (De la Guerra) puede ser interpretado en una diversidad de registros y significados. En una época en la que los estudios superiores se han especializado y en algún sentido parcelado, Vom Kriege es una prodigiosa obra teórica, que articula distintos niveles y sintetiza diversas fuentes. Con anclaje en la experiencia y focalizada en la perspectiva de la conducción del Estado, contiene conceptos fundamentales de relaciones internacionales, filosofía política, estrategia, operaciones bélicas e historia militar. Pero de modo sobresaliente, Vom Kriege es un libro de teoría política, una summa de pensamiento político-militar fundamentada en una meditación sobre la naturaleza humana y la gama de sus posibilidades.

Un libro de esa naturaleza ha llamado más la atención a grandes políticos y militares del pasado que a los científicos sociales. Aunque su influencia fue notable en ambientes políticos y militares desde mediados del siglo XIX hasta el

1 La última edición crítica a la que accedimos es: Vom Kriege, Bonn, Dümmlers Verlag, 1991. Por otra parte, hay una excelente versión castellana traducida por R.W. de Setaro (1960), De la Guerra, Buenos Aires, Ediciones Mar Océano. siglo XX, el meridiano de sus lectores se desplazó recién en los últimos años hacia el campo de las ciencias humanas. En este aspecto Raymond Aron cumplió la tarea principal, pues abordó Vom Kriege en una serie de investigaciones coronadas en un estudio monumental (1989).

Como militar, Clausewitz fue integrante aventajado de la escuela de los reformadores militares de la Prusia liderada por Sharsnhorst y Gneisenau, que trabajaron para transformar el ejército prusiano después de las derrotas frente a Napoleón. Pero la excelencia de Vom Kriege lo ubica en una posición superior a los escritores militares de la época. Por cierto, lo que en Vom Kriege hay de estrategia operacional y táctica militar en gran medida está perimido por doscientos años de avance tecnológico y cambios en el modo de combatir. Aquí no evaluamos ese aspecto de su pensamiento, ni tampoco las guerras, doctrinas y modos de combatir de las primeras décadas del siglo XIX. Por otra parte, en esos años, los autores militares más leídos por los jefes y oficiales superiores fueron Guibert, von Bülow y Jomini, cuya influencia en la formación y el lenguaje de la estrategia y en el concepto y desarrollo de lo táctico fuera erróneamente subestimada en los ámbitos no militares (Palmer, 1968:121-210; Howard, 1968:13-35).

Los aspectos técnico militares dificultan la lectura desde la ciencia política, pues requieren del cuadro histórico de relaciones entre la condición política y el modo de combatir. Las expresiones filosóficas, en cambio, dificultan la in- 
terpretación en las academias militares, apremiadas por la actualización de manuales de operaciones más que por la meditación sobre cuestiones hermenéuticas.

El trabajo crítico desliga a Clausewitz de su aparente belicismo y lo devela como teórico político. Las investigaciones más importantes subrayan el carácter inconcluso de Vom Kriege, la orientación de la revisión del tratado ${ }^{2}$ proyectada, la relación entre guerra absoluta y guerra real, la conexión con los ambientes literarios y políticos de su tiempo, la crítica de las interpretaciones incautas, la vigencia en los grandes conflictos del siglo XX, etc. (Aron, 1960; Howard, 1969; Paret, 2007).

Más allá de la influencia sobre políticos y militares, tratada adecuadamente en otros textos (Ancona, 1979; Aron, 1989), para la teoría de las relaciones internacionales Clausewitz es un antecedente de la escuela realista. Por otra parte, sus cultores conforman una especie en sí misma, los neoclausewitzianos, que pueden distinguirse en tres clases: exégetas, analistas y línea intermedia.

Los exégetas centran la atención en la interpretación del pensamiento de Clausewitz, y la hermenéutica- en el estilo de Schleiermacher- busca el significado cada vez más profundo en la relación entre el todo y las partes en el interior de la obra. Podemos encuadrar como exégetas a autores como Schmitt (1968), Lenin (1979), Paret (1968), Gluksmann (1969) y Kondylis (1988).

2 Llamamos «tratado» a Vom Kreige, como lo denominó Raymond Aron.
Los analistas, en cambio, asumen con menos juicio crítico determinadas tesis clausewitzianas y las aplican a la investigación de los conflictos y situaciones concretas. Entre ellos destacamos a Kissinger $(1968$; 1976), Brodie (1973), Howard (1976) y Hoffman (1987).

Finalmente, la línea intermedia anilla los círculos hermenéuticos en el interior del texto, y entre el texto y diversas situaciones históricas. Inscribimos a Aron (1960; 1989), Rapoport (1992), Luttwak (1992), Hoffman (1987), Holsti (1996), Van Creveld (1985; 2008).

Por cierto, la clasificación es sumaria y, en algún sentido, arbitraria, pues hay vasos comunicantes y combinaciones entre las diversas ramas de la especie.

Consideramos a Clausewitz como teórico político de la guerra y no como belicista o ideólogo de ocasión. En un corte hermenéutico intencional, la analítica de Vom Kriege permite explorar núcleos conceptuales relevantes para la teoría de las relaciones internacionales. Porque Clausewitz se inscribe en la gran tradición de Tucídides, Maquiavelo y Hobbes, Vom Kriege será lo que ha sido desde su aparición: una fuente de posibilidades analíticas.

Las disciplina científica de las relaciones internacionales revela cierta heterogeneidad de carácter, objeto y metodología (del Arenal, 1994:1937). La lectura de Vom Kriege puede contribuir cuanto menos a señalar la importancia de una teoría política de la guerra, orientada a la práctica, y provista de metodología dialéctica para 
la captación del movimiento real. Asimismo, una serie de cuestiones abiertas estimulan la posibilidad de nuevos horizontes interpretativos. Por caso, la investigación de las fuentes, el método, la ubicación en el pensamiento político occidental, y los posibles significados de un clásico como Clausewitz serán siempre cuestiones problemáticas y estimulantes.

Por lo demás, en la actualidad iberoamericana, las tensiones conforman un marco apropiado para la lectura de Clausewitz. Desde luego, no se trata de agitar una percepción apocalíptica, sino más bien de afinar el instrumento teórico para apreciar las correlaciones entre las virtualidades lógicas y las condiciones concretas, pues la relación entre lo absoluto y la realidad está surcada por la temporalidad. Por cierto, la teoría de Clausewitz opera en sentido contrario a la tendencia al olvido del fundamento del régimen de la democracia liberal.

Como teórico de la guerra y la paz como partes estructurales de la política, Clausewitz acude a la comprensión de nuestra circunstancia. La situación iberoamericana actual combina retórica de guerra civil, diplomacia de congresos y seguridad colectiva sin mecanismo efectivo de sanción.

En el presente artículo sostenemos que Vom Kriege articula intenciones y capacidades, entendimiento y sentimientos, pueblos, ejércitos y estadistas en unidad superior, en la que lo clásico domina a lo romántico y la naturaleza se impone sobre la convención.
Por distintas notas, tanto esenciales como formales, observamos que la documentada familiaridad de Clausewitz con los círculos literarios de Berlín y con la literatura alemana de su tiempo marca una impronta en Vom Kriege (Paret, 2007: 75-125). Por cierto, la influencia de Goethe sobre la cultura alemana fue rectora entre los años 1790 y 1832, que comprende el tiempo de Clausewitz (Stael, 1947: 5862 y 107-121; Heine, 1943:153-280; Aesch, 1947; Meinecke, 1982: 379496; Spranger, 1948:79-103). El peso de Goethe en la gran cultura alemana de aquellos años es difícil de apreciar en una situación histórico- espiritual como la nuestra. En la senda de Rousseau y Kant, Goethe -desde fuera de la Universidad- es quien más influyó en la Universidad y la cultura alemanas.

El colapso cultural de Alemania por el nazismo, la guerra, la división y la reunificación intelectualmente insípida, en un ambiente posmoderno y deconstructivista, dificulta la convergencia de horizontes de la labor interpretativa y nos muestra el resplandor de un pasado cerrado. El horizonte intelectual de Alemania al inicio del siglo XIX es muy distinto del nuestro, y muchas de las dificultades interpretativas radican en la literalidad de las lecturas influidas por el positivismo. Una lectura de Vom Kriege enfocada en estos aspectos puede contribuir a la interpretación del legado clausewitziano en su conjunto. 


\section{FUENTES Y SIGNIFICADOS DE VOM KRIEGE}

Clausewitz utiliza una gama de materiales diversos. Hay cuotas importantes de romanticismo y clasicismo, de dialéctica e idealismo alemán, de Fichte y $\mathrm{Na}$ poleón, de ciencia natural e historia. Pero las influencias no establecen causalidad, más bien aportan elementos refundidos en el crisol de un pensamiento original, cuyo núcleo irradia una totalidad en sí misma. Por cierto, Vom Kriege es una obra inconclusa, iniciada en 1816, y considerando la Nota final y la Advertencia de 1827, debía revisarse y modificarse en su conjunto (Aron: 1989: 71-80). Solo el capítulo 1 del libro primero puede considerarse concluido. En la Advertencia de 1827 Clausewitz sostiene la necesidad de revisión de Vom Kriege en función de dos principios: la primacía de la política y las dos especies de guerra.

Como en los jirones de una antigua estatua romana, Vom Kriege muestra que el pensamiento de Clausewitz es una totalidad, que incardina categorías y fenómenos en orden dialéctico. Si pudiéramos recurrir a una terminología hoy en desuso, diríamos que Vom Kriege es una unidad espiritual materialmente fragmentaria. En analogía con Kant, es una crítica de la razón estratégica, en lo teórico y lo práctico.

Frente a ciertas interpretaciones, entendemos que Vom Kriege no solo es un texto comprensivo sino también normativo, al servicio de la vita activa. Por cierto, la caracterización de Von Kriege como libro no normativo pre- senta el equívoco entre la vida activa y el procedimiento técnico. Vom Kriege es un pensamiento sobre la acción, una elucidación del drama viviente que se despliega en el teatro de la guerra. La comprensión de la naturaleza y las posibilidades de la guerra configura una teoría práctica, no en función de procedimientos técnicos, sujetos a la contingencia temporal, sino como analítica de las condiciones de posibilidad de la acción militar eficaz, subordinada a la política como lucha por los fines.

El Prefacio bosqueja la relación entre teoría y práctica, y en tanto "análisis abstracto y observación, filosofía y experiencia, no deben despreciarse ni excluirse recíprocamente: cada término es garantía del otro» (1960: 27). La analogía con el dualismo kantiano no debilita la conciencia de la tensión entre los esquemas trascendentales y los fenómenos de la experiencia, aunque se oriente en sentido opuesto al devenir idealista de la filosofía alemana poskantiana. Cuando el hilo del pensamiento se distancia de la praxis, Clausewitz prefiere romperlo y atenerse a los fenómenos de la experiencia. La primacía de la experiencia sobre la formalización bien puede ser producto del recelo del hijo de los campamentos con los torbellinos del idealismo alemán. Pero también, acaso, se encuentra en plena coincidencia con el influjo clásico ejercido principalmente por Goethe (Stael, 1947: 58-62; Heine: 1943. 102-143) ${ }^{3}$.

Ver Goethe (1999: 20, 75): «O wie fúhl ich in Rom mich so froh! Gedenk ich der 
Schiller pudo distinguir entre poesía ingenua y poesía sentimental pensando en Goethe como arquetipo de lo ingenuo. Homero, Shakespeare y Virgilio fueron maestros de Goethe, porque trascienden la circunstancia y ascienden a lo universal, y lo específico envolvente de una cultura deja paso a la naturaleza liberadora. Schiller fue un lector privilegiado de Homero y su interpretación es una obra en sí misma, creadora de una literatura nacional fundacional. Sin embargo, grandes pensadores como Kant y Schiller abrieron la sospecha sobre la posibilidad misma del espejo de la naturaleza que Goethe apreciaba en Shakespeare y que Schiller caracterizó de ingenuo. Tanto el método inductivo como el hipotéticodeductivo, dominantes en los siglos XIX y XX, comparten el supuesto de la disyunción radical entre el hombre y la Naturaleza. Para Clausewitz, en consonancia con Goethe, la mente humana puede penetrar en la naturaleza de las cosas y a partir de ahí alcanzar principios y nociones que incrementen el conocimiento de los fenómenos. Es lo

Zeiten, Da mich ein graulicher Tag hinten im Norden umfing, Trübe der Himmel und schwer auf meinde Scheitel sich senkte, Farb- und gestaltlos die Welt um den Ermatteten lag. Und ich über mein Ich, des unberfriedigten Geistes Düstre Wege su spähn, still in Betrachtung versank». «Como me siento en Roma feliz cuando recuerdo, los tiempos en que el gris me rodeaba en el norte, pesaba y me abatía el cielo hosco y nuboso, envolvía el mundo informe e incoloro al exhausto, y yo sobre mi yo cavilaba en silencio, viendo los sombríos cauces del alma insatisfecha». que Goethe denomina «delicado empirismo» (Zarte Empirie), que previene la precipitación idealista y constituye una expresión particular de una modalidad subyacente en la historia de la filosofía desde los orígenes, que encuentra su culminación idealista en el método fenomenológico.

Clausewitz aparece como un pensador original, de gran fuerza expresiva, pero autodidacta en filosofía. Aron señala semejanzas con Kant y Montesquieu (1989: 272-284). Autores decisivos en la fundación del mundo moderno como Hobbes, Locke y Rousseau tenían en común con los filósofos griegos una amplia meditación sobre el modo originario de ser de las cosas. El estado de naturaleza era el último estrato en el que podía apoyarse la idea del hombre y la sociedad. Los modernos sometieron a crítica las ideas de Platón y Aristóteles, pero coincidieron con ellos en la importancia de la Naturaleza en la construcción de la idea del hombre y la sociedad. A diferencia de nuestro ambiente histórico-espiritual, no podían conformarse con opiniones ni valoraciones como base de los juicios políticos y morales. El pensar puede ser un hacer de amplio alcance en la medida en que descansa en una ontología coherente, o en una crítica igualmente coherente de la ontología. De este modo, Rousseau destacó el carácter maleable de la naturaleza humana y Kant extrajo la conclusión decisiva: la posibilidad de la conducta moral reposa en la condición formal de universalización, no en la naturaleza. 
Por el contrario, Vom Kriege encuentra su fuerza siempre renovada en la restitución de los derechos de la naturaleza frente a las convenciones jurídicas y militares. En este aspecto, la disidencia de Clausewitz con Montesquieu y Kant es superior a cualquier semejanza, y Vom Kriege se constituye en oposición fundamental a la creencia en el comercio como artífice de la paz perpetua, y en el fundamento de otras oposiciones derivadas. En sintonía con Tucídides, Clausewitz no menciona a la economía ni al comercio.

En nuestra época, caracterizada por la multiculturalidad y el relativismo moral, la dimensión absoluta y natural de un fenómeno como la guerra aparece como extraña, «ingenua».En cambio, para Clausewitz, la determinación de la naturaleza de la guerra proporciona el fundamento del pasaje de lo más simple y abstracto a lo más concreto y rico en determinaciones, de los conceptos puros («simples») a los conceptos sintéticos («complejos»), en los que articula la diferencia entre la guerra absoluta (absoluter Krieg) y la guerra real (wirklicher Krieg). "Nos proponemos considerar, en primer lugar, los diversos elementos de nuestro tema; luego sus distintas partes o divisiones y finalmente el todo en su última conexión. Procederemos, de este modo, de lo simple a lo complejo. Pero en esta cuestión, más que en alguna otra, es necesario comenzar por referirse a la naturaleza del todo, ya que en esto la parte y el todo deben ser considerados simultáneamente» (1960:9).
La relación entre el todo y la parte configura una identidad estructural. Friedrich Schlegel afirmó que el Wilhelm Meister de Goethe era una obra de arte «perfectamente orgánica» en la que «las partes reiteran el todo, y un espíritu crítico puede vislumbrar la concepción completa sobre la base de un único fragmento pues [...] todos los elementos de la novela dependen uno del otro, en tanto etapas metamórficas y manifestaciones sucesivas del mismísimo principio».(Aesch, 1947: 179). Schlegel comparó el Wilheim Meister de Goethe, la Doctrina de la Ciencia de Fichte y la Revolución francesa (Athenaeum, 1798: 187). La reflexión de Schlegel pudo parecerle a Carl Schmitt «el reflejo de un fuego muy lejano» (2000: 84) y una manifestación pasajera. A propósito, Carl Schmitt fue un historicista radical que desarrolló una teoría de lo político en la que lo importante es quien se decide contra quien hic et nunc. Sin embargo, un lector como Goethe pudo entrever en la Doctrina de la Ciencia a Napoleón como el YO que sobrepone y supera la contraposición de Yo/ No Yo. Análogamente, Los años de aprendizaje de Wilhem Meister abordan en el trasfondo de las guerras de la Revolución francesa el problema del destino y la fuerza del sujeto para enfrentarlo, sostenerse y vencerlo. Por cierto, la Revolución francesa y luego «el Dios de la Guerra» torcieron el destino de Europa, y Fichte reclamó para Alemania una filosofía de la libertad opuesta a la "filosofía del extranjero", que proponía acomodarse a un me- 
canismo impulsado desde afuera, en suma, «el fin de la historia». Schlegel halló dignos de comparación y elogio la Revolución francesa, el Wilheim Meister y la Doctrina de la Ciencia pues en los tres la actividad del sujeto se impone frente a la estabilidad de las condiciones reales. Así las cosas, Schlegel no estaba $\tan$ equivocado.

Clausewitz expresa también el entusiasmo de la nueva época en la teoría política sobre la guerra. La historia de la guerra anterior a la Revolución francesa es un proceso de ablandamiento en el que predominan la maniobra y la demostración por encima del choque y la acción. Las guerras de la Revolución, sus grandes objetivos, y la movilización de las masas ciudadanas nacionales prepararon el kairós para la aparición del «Dios de la Guerra». Toda la convención dieciochesca fue barrida por la fuerza de la Naturaleza, por la revolución política encauzada en el arte militar por Napoleón, y en la teoría de la guerra por Clausewitz.

«Esta forma de considerar las guerras en las que se participaba debido a las alianzas, prevaleció durante mucho tiempo y solo en la época moderna se vio obligada a dejar paso al punto de vista natural, cuando el peligro extremo condujo el pensamiento de los hombres por senderos naturales (como contra Bonaparte) y cuando el poder ilimitado los obligó a adoptarlo (como bajo Bonaparte)» (1960:564). La naturaleza de la guerra es la guerra considerada de acuerdo a su esencia, como fenómeno originario (Urphänomen), que brota de la polaridad (Polarität) constitutiva de la naturaleza de las cosas. En cambio, las limitaciones de la guerra de los años previos a «Bonaparte» constituyen «una tradición profundamente arraigada en las limitaciones naturales y en las debilidades de la naturaleza humana» (Ibid). El entramado de las convenciones surge a partir del miedo a la muerte violenta, y éste supone la voluntad de matar: esa es la polaridad de la naturaleza humana detrás del velo.

Clausewitz no es historicista ni es mera expresión de la Revolución francesa en el plano militar. La incorporación de las masas populares en las guerras no comenzó en la era de las nacionalidades ni es un fenómeno inédito en la historia. En todo caso, las guerras de la Revolución reanudaron una modalidad que había permanecido oculta en buena parte del siglo XVIII, pero que integraba la recurrencia histórica. El pueblo que durante las invasiones tártaras lo era todo en la guerra, que en las antiguas repúblicas y en la Edad Media tenía gran importancia (si restringimos apropiadamente la idea a los que poseían realmente los derechos de ciudadanos), en el siglo XVIII no representaba, en forma directa, absolutamente nada y solo conservaba una influencia indirecta sobre la guerra a través de sus virtudes y faltas generales» (Clausewitz, 1960:549). El historicismo postula la novedad radical de la temporalidad, abierta a la creación del sujeto, en la que la idea está situada en tiempo y lugar, y solo en esa relación guarda sentido. 
La radicalidad de Vom Kriege en la búsqueda del estado de naturaleza expresado como plano absoluto es el modo de fundamentación de una teoría realmente acorde con las contradicciones y alternativas fundamentales de la condición humana. En Vom Kriege, la primera definición establece que la esencia de la guerra es el duelo (Zweikampf), la lucha entre sujetos. Aron asoció el duelo con el Idealtypen weberiano, una imagen estilizada del fenómeno empírico, perteneciente a un modo de pensar con menor radicalidad. Nos parece más apropiado sugerir que Clausewitz sigue el modelo de fenómeno primigenio (Urphänomen) de Goethe, en el que el contenido intelectual permanece íntimamente imbricado al fenómeno empírico. El Urphänomen es una unidad de idea y experiencia real, un fenómeno espiritualizado cuya idealidad compenetra la existencia real y lo llena de vida, dirección y desarrollo. En este aspecto, la interpretación del Zweikampf como fenómeno primigenio (Urphänomen), que la experiencia recapitula, posee la fuerza expresiva y la intensidad espiritual/ real constitutiva del pensamiento fundamental de Vom Kriege.

Para Clausewitz, la moral solo es concebible en el interior de los Estados y bajo la ley (1960:9). Fuera de los Estados, el derecho y los usos aparecen como «restricciones insignificantes» (Ibid: 14). Clausewitz supone la natural inocencia (no puede haber fuerza moral sino únicamente física) del estado de naturaleza y del estado de guerra. De este modo, se inscribe en el interior de la sistemática del liberalismo moderno de raíz hobbesiana. En las relaciones interestatales, se impone la inclinación natural. La libertad de elección de las alternativas morales, la distinción entre el bien y el mal, el reino de los fines o cultura en sentido kantiano, es válida en el interior de los Estados. La política internacional es historia determinada por el estado de naturaleza: el arte de la guerra prolonga a la naturaleza.

El plano absoluto busca la representación finita de lo infinito y posibilita arraigar la teoría en un fundamento sólido para adentrarse progresivamente en las guerras reales. La definición de la guerra como duelo en una escala más amplia es el punto de partida para la inclusión de mediaciones concretas. La guerra absoluta (absoluter Krieg) es la caracterización formal, abstracta. La introducción de determinaciones reales transforma su condición. De acuerdo a su naturaleza, el choque de los duelistas conduce al ascenso a los extremos. La magnitud de las fuerzas está recíprocamente determinada en un proceso ascensional, que termina con el abatimiento de uno de los contendientes y la victoria del otro. Clausewitz construye la relación entre Zweikampf, absoluter Krieg y wirklicher Krieg (duelo, guerra absoluta y guerra real) como tránsito del fenómeno primigenio a lo concreto real con mediación de lo absoluto. La usual identificación de Zweikampf (duelo) y absoluter Krieg (guerra absoluta) confunde el fenómeno primigenio con el concepto absoluto. 
La distinción entre ambos constituye un método en tres momentos, pues parte desde el fenómeno primigenio como Zweikampf (duelo), atraviesa la mediación de lo absoluto formal en tanto absoluter Krieg (guerra absoluta), y accede al fenómeno empírico a modo de wirklicher Krieg (guerra real). Finalmente, esta presenta dos especies: la primera especie, análoga al concepto de absoluter Krieg (guerra absoluta), pues concluye en el aniquilamiento de las fuerzas de uno de los contendientes y la victoria del otro, y la segunda especie, que concluye en la paz negociada y la observación armada. Luego, hay una serie de polaridades y modalidades de manifestaciones empíricas posibles.

La semejanza entre guerra absoluta y primera especie de guerra introduce una dificultad adicional al pensamiento de Clausewitz: el concepto de absoluter Krieg (guerra absoluta) es semejante a la guerra de la primera especie. La guerra absoluta no es una directiva para la acción, pero tampoco un desvarío. Es una visión formal que encuentra una especie análoga y otra muy distinta.

En el pasaje de la mediación absoluta al fenómeno real, supera la abstracción, y avanza hacia la realidad concreta: el movimiento es comprensible si se considera el modo de despliegue teórico: fenómeno primigenio -concepto absoluto- fenómeno real (dos especies).

\section{III.La dialéctica de Clausewitz}

La unidad entre literatura y ciencia, filosofía y política, fue sobrepasada por el desarrollo científico y la división del conocimiento. La puesta entre paréntesis de lo que hoy entendemos como discurso científico puede aproximarnos a la comprensión del vocabulario científico de la Alemania de comienzos del siglo XIX. Los métodos inductivo, hipotético-deductivo y la hermenéutica tienen en común la ligazón de la idea a la circunstancia y la provisionalidad de la verdad. Para nuestra situación histórico-espiritual, las ideas son partes de concepciones del mundo y se inscriben dentro de paradigmas: es imposible conocer la naturaleza de las cosas. La idea que Shakespeare presenta las posibilidades fundamentales de la experiencia humana es ajena al modo de pensar contemporáneo. La unidad del saber conectaba a la literatura y la ciencia en un común anclaje en la realidad. De este modo, la idea goetheana de morfología y metamorfosis surge en el campo de la botánica y se extiende a otras ramas del árbol de la sabiduría. Pudo decir Dhilthey que en Alemania hasta los niños sabían que Goethe enseñaba metamorfosis. Algo así acontece con las nociones de contradicción, sistema, estructura, caos, etc. La raíz común del conocimiento se resiste a abandonarnos.

A principios del siglo XIX la teoría de los colores de Goethe redescubre la dialéctica mediante el esquema de la gama cromática, que combina po- 
laridad y ascenso. La mezcla de dos colores primarios desata un momento productivo y deviene un nuevo color. De este modo, se produce el pasaje de la dialéctica binaria en la que el ente se desgarra y aniquila a si mismo, a una dialéctica ternaria en la que la polaridad origina un tercer término superior. La dialéctica binaria aniquiladora y la dialéctica ternaria productiva configuran respectivamente el fundamento de la guerra absoluta y la guerra real. «El principio de polaridad sólo es válido en la cosa misma, en la cual lo positivo y su contrario, lo negativo, se destruyen mutuamente. En una batalla, cada uno de los bandos desea vencer; ésta es una verdadera polaridad». En cambio, las dos formas de hacer la guerra, el ataque y la defensa, "son cosas muy diferentes y de fuerza desigual [...] la polaridad reside en la relación, en la decisión» (Clausewitz, 1960: 19). La polaridad aniquilante se manifiesta en la batalla, que es el choque de dos fuerzas y pertenece al campo de la táctica. La polaridad productiva enfrenta estrategias, es decir, combinaciones ofensivas y defensivas de batallas. Por ello puede desembocar en un tercer término, la paz negociada.

En el capítulo 1 del Libro Primero de Vom Kriege las definiciones de la guerra parecen divergentes, ya que pasa de sostener que «la guerra es un acto de violencia destinado a constreñir al adversario a ejecutar nuestra voluntad» a una definición en tres términos. El camino que conduce de la definición original a la definición trinitaria está sembrado de ideas y apreciaciones que hacen de Vom Kriege "un tesoro de citas» (Aron, 1989).

La dialéctica clausewitziana despliega oposiciones y polaridades en sentido concreto. El pasaje de lo abstracto a lo concreto es un desarrollo de síntesis de dimensiones empíricas en el movimiento dialéctico entre el punto de partida (el duelo) y el punto de llegada (la totalidad política). La diferencia entre los conceptos guerra absoluta, guerra real y extraña trinidad proporciona la clave de acceso a la teoría, cuyo desconocimiento es la fuente de los malentendidos.

Las polaridades entre fuerzas morales/ fuerzas materiales, intención hostil/ sentimiento hostil, defensa/ ataque, táctica/ estrategia, fin de la guerra/ objetivos en la guerra, etc., configuran una totalidad dialéctica que desemboca en las dos especies de guerra. La guerra se entrelaza en las tensiones entre el fin político (Zweck) y el objetivo militar (Ziel), en el juego de las pasiones y el entendimiento, y está librada a la intempestiva fortuna. Por cierto, la fuerte influencia que Maquiavelo ejerció en la formación intelectual de Clausewitz emerge en la importancia del azar y la incertidumbre. No hay recetario ni fórmulas para triunfar en la guerra porque el movimiento de intenciones, fuerzas, pasiones y azares que intervienen colocan al jefe en la situación de hacer un esfuerzo superior al de Newton (Clausewitz, 1960: 545).

La dialéctica de polaridad y ascenso en la totalidad concreta reúne en un 
nuevo plano las ideas anticipadas en el nivel abstracto y asume los elementos analíticos, subordinándolos a la primacía de lo político. La relación entre las fuerzas materiales y morales, el ataque y la defensa, lo intelectual y lo afectivo, el fin y los medios, en suma, todos los aspectos esbozados anteriormente, adquieren orden y concatenación bajo la función rectora y determinante de la política.

Clausewitz afirma que «la guerra [...] no es solamente un verdadero camaleón, por el hecho de que en cada caso cambia en algo su carácter, sino que es también una extraña trinidad, si se la considera como un todo, en relación con las tendencias que predominan en ella»(1960: 26) La «extraña trinidad»(wunderliche Dreifaltigkeit) es la figura de la morfología de las formaciones enfrentadas en la guerra El tránsito de una especie a otra, en principio determinado por el cambio en las relaciones entre el fin político (Zweck) y el objetivo militar (Ziel), transforma la fisonomía de la guerra. La guerra como camaleón permite enlazar la trinidad como núcleo de determinación principal desde el interior de los sujetos enfrentados:

Esta trinidad la constituyen el odio, la enemistad y la violencia primitiva de su esencia, que deben considerarse como un ciego impulso natural, el juego del azar y las probabilidades, que hacen de ella una actividad libre de emociones, y el carácter subordinado de instrumento político, que hace que pertenezca al dominio de la inteligencia pura. El primero de estos tres aspectos interesa especialmente al pueblo; el segundo al jefe y a su ejército y el tercero solamente al gobierno [...] estas tres tendencias que se manifiestan con fuerza de leyes, reposan profundamente sobre la naturaleza del sujeto y al mismo tiempo varían en magnitud (Ibíd).

La «extraña trinidad» contiene tres partes estructurales de los sujetos. La confluencia del odio (Hass), la enemistad (Feindschaft) y la violencia primitiva de su esencia (ursprüngliche Gewaltsamkeit) como ciego impulso natural (blinder Naturtrieb) corresponde al pueblo (Volk), que representa el estado de naturaleza negado y conservado como negado (Aufhebung) por la acción de los dos niveles superiores de la «trinidad», sin los cuales la guerra no podría ser lo que es. Es decir, medio serio para un fin serio y prolongación de la política con medios violentos. La segunda parte es más elevada: el juego del azar y las probabilidades, que remiten al talento y el valor de la actividad libre del alma, corresponde al jefe militar. La diferencia con la escuela de base geométrica se manifiesta en la apreciación de la estrategia de las operaciones militares como un verdadero arte, y del jefe militar como creador. La tercera parte es el entendimiento que pertenece al gobernante político y determina a la guerra como instrumento político subordinado.

La unidad de las tres partes y la modalidad concreta de articulación en cada caso determinan la especie de guerra. La relación entre morfología 
y metamorfosis clarifica la «extraña trinidad», y posibilita dar cuenta de la particular combinación histórico concreta que aproxima o aleja a una guerra real del concepto de guerra absoluta. La figura de la trinidad asemeja el Estado con un "macroantropos» (Aesch, 1948: 236), un hombre en gran escala. El organicismo en tanto concatenación del todo y las partes se desliza hacia el antropocentrismo, que asemeja el hombre, la comunidad y el cosmos. Platón y Aristóteles incardinaron virtudes y vicios entre hombre y régimen politico. Clausewitz tradujo dimensiones del alma a dimensiones de la comunidad y renovó la misteriosa analogía entre el hombre, la ciudad y el cosmos.

La extraña trinidad vincula una facultad del alma con un estrato específico del organismo colectivo. Platón distinguió tres partes en el alma: sensitiva, irascible e inteligible. La analogía se presenta por sí sola. La extraña trinidad no es una categoría del sujeto de conocimiento, sino un predicado de lo real. El fundamento de la extraña trinidad no es la tabla de las categorías kantianas si no más bien el antropocentrismo y la idea orgánica, ubicados en la tradición abierta por los griegos.

La prudencia política sugiere el desarrollo equilibrado de las tres partes. En las personas, el dominio del entendimiento sobre las pasiones configura el carácter adulto. En los animales, el desarrollo completo de los instintos consuma las posibilidades vitales. En cuanto a despliegue de virtualidades, cuando alcanza la pubertad, el animal está acabado. En el hombre, en cambio, el desarrollo de las pasiones pone en acción a la voluntad y al entendimiento, que luchan por dominarlas. Esa lucha es educación, formación, Bildung. En el pasaje del estado de naturaleza a la sociedad civil mediante la Ilustración, aquel misterio de la naturaleza reaparece en la política.

\section{LA FÓRMULA}

La política aparece en Clausewitz como una totalidad dominante. Puede distinguirse la política como situación (politics) y como línea de acción (poli$c y)$, (Aron, 1989: 128-133). En ambos casos, la política es paz en acto y guerra en potencia, o la contraria, guerra en acto y paz en potencia. Como situación (politics) toda paz lleva en sí los gérmenes de una futura guerra, y toda guerra contiene en sí una futura paz. En cambio, como línea de acción (policy) se presenta una doble dificultad. Por un lado, el caso obvio del acto pacífico que también es pacífico en potencia. Es la paz en acto y en potencia. La paz perpetua resultaría del reino definitivo de los justos sobre la tierra. En contraposición al idealismo, un teólogo protestante como Niebuhr, apoyado en la interpretación sincrónica de las Sagradas Escrituras, construyó una teoría realista de las relaciones internacionales que acentúa el pecado original del Hombre y contradice la interpretación cristológico-humanista (Niebuhr: 1944: 21-100; 1965: 81-99; 1966: 62-87). 
Pero también cabe pensar en la guerra que tiene como fin su propia reproducción. Una guerra de ese tipo fue denominada por Kalevi Holsti como de la «tercera especie» (1996). Los nazis, las bandas narcoterroristas y las fuerzas militares de los señores de la guerra de África se ubicarían entre los promotores de la guerra de la tercera especie. El fin de esa guerra no es un cierto tipo de paz sino la mera reproducción de la guerra, de la que emergen negocios ilegales, modos de vida, etc. El argumento de una tercera especie de guerra es fuerte y no carece de atractivo. En algún sentido, el nihilismo activo de Nietzsche comporta una acción así. En lugar de la paz perpetua como reino del comercio pacífico, el superhombre (Übermensch) en acción dionisíaca haría de la vida en la tierra una perpetua orgía de sangre. Por cierto, el Tercer Reich por mil años podía ser un delirio condenado a un sinnúmero de guerras previas, pero divisaba una situación de paz imperial esclavista al final del recorrido. La teoría de la revolución permanente de Trotsky y su derivada inconfesada, la teoría de la revolución ininterrumpida de Mao Tse Tung, no obstante sus consecuencias, proponen un orden pacífico comunista en el fin de la historia. En el caso de los señores de la guerra y los narcoterroristas, nos parece que Clausewitz no hubiera aceptado como guerra al delito perpetuo, ni al crimen organizado. La objeción a Kal Holsti se apoya en Clausewitz, que guarda como correlato orgánico a los Estados, no a las bandas de delin- cuentes. En relación con los partisanos, la reivindicación de objetivos revolucionarios o de independencia nacional confiere entidad política. Toda la pelea por el reconocimiento o la negación de la condición beligerante pertenece de lleno a la lucha política: el partisano busca cuartel, el ejército convencional se lo niega, pues el partisano lleva en sí un proyecto de aniquilamiento y relevo de ése ejército y de ése Estado. Sin embargo, en los «señores de la guerra» y demás organizaciones interesadas en la violencia perpetua, entendemos que manifiestan en acto algo que toda sociedad civil lleva en potencia: la absorción de la civilización por la naturaleza. El entramado entre el estado de naturaleza y la sociedad civil que lo niega como acto y lo conserva como potencia, configura la polaridad más inquietante de un pensamiento político a la altura de lo humano. Naturaleza e historia, inclinación y deber, pasiones y entendimiento, replican la relación entre physis y nomos. No se trataría pues de una tercera especie de guerra sino de la disolución de la guerra en la mera violencia, la pérdida cuanto menos de la parte superior de la trinidad, y el retorno a una era de barbarie ${ }^{4}$.

Para Clausewitz la guerra está determinada por fines constitutivos de una determinada paz. La frase que define a la guerra como "continuación de

\footnotetext{
4 Nos parece una metáfora adecuada del hundimiento de la civilización en el estado de naturaleza la frase que escribe Joseph Conrad al final de El Corazón de las tinieblas (Heart of darkness): «oh, el horror, el horror».
} 
la política por otros medios» aparece tres veces en Vom Kriege: como título del punto 24 del capítulo 1 del Libro primero titulado «La guerra es la mera continuación de la política por otros medios»; luego cuando afirma que «la guerra no es simplemente un acto político, es un verdadero instrumento político, una continuación de la actividad política, una realización de la misma por otros medios»; por último, en el punto B del capítulo 6 del Libro VIII, titulado «La guerra como instrumento de la política», destaca la imbricación estructural de la guerra en la política como un todo, cuando afirma «Habríamos considerado esta unidad desde el principio, si no hubiera sido necesario subrayar estas contradicciones evidentes y considerar también separadamente los diferentes elementos. Esta unidad es la concepción de que la guerra es sólo una parte del intercambio político y, por lo tanto, en ninguna forma constituye una cosa independiente en sí misma». (565).

La inversión de la fórmula (la política es la continuación de la guerra por otros medios) confunde el significado del término "continuación», ya que no es solo temporal diacrónico sino estructural sincrónico. No significa mero estadio posterior, sino parte estructural del mismo todo continuo. La guerra no reemplaza ni permuta a la política sino que despliega una de sus posibilidades. "En una palabra, en su punto de vista más elevado, el arte de la guerra se transforma en política, pero, por supuesto, en una política que libra batallas en lugar de escribir notas diplomáticas» (1960: 568). La clave de la política es la unidad dialéctica de los fines y las inclinaciones.

La identificación de la política con la eventualidad del enfrentamiento armado ejercerá un importante influjo en la teoría de lo político de Carl Schmitt, el crítico más agudo y persistente de la paz perpetua kantiana:

La específica distinción política a la cual es posible referir las acciones y los motivos políticos es la distinción de amigo (Freund) y enemigo(Freind) (...) La guerra no es pues un fin o una meta, $\mathrm{o}$ tan sólo el contenido de la política, sino que es su presupuesto siempre presente como posibilidad real y que determina de modo particular el pensamiento y la acción del hombre, provocando así un comportamiento político específico(...) El enemigo es simplemente el otro, el extranjero (der Fremde) y basta a su esencia que (...) en el caso extremo sean posibles con él conflictos que no puedan ser decididos ni a través de un sistema de normas preestablecida ni mediante la intervención de un tercero 'descomprometido' y por eso 'imparcial'.

(Schmitt, 1985:15-76).

Apoyados en la oposición radical entre la política y la guerra, y en la confusión del accidente con la sustancia, los autores del Tratado de Versalles impusieron la reducción del ejército alemán como una de las condiciones para la paz perpetua. Clausewiz enseña que la política posee prioridad ontológica y práctica sobre diplomáticos y soldados, y extrae la consecuencia práctica de la subordinación del objetivo militar 
(Ziel) al fin político (Zweck). En un estado de naturaleza recurrente, Israel presenta un muestrario de la teoría. Guiados por fines políticos, viejos guerreros como Menahem Beguin e Isaac Rabín desempeñaron brillantes misiones diplomáticas, pues diálogo y combate son funciones intercambiables de la política.

El jefe político estatal es la inteligencia del Estado personificado: asume el conocimiento de la totalidad política. El jefe militar también es político, pero concentra su actividad en una parte de la política, la que intercambia disparos. Como la parte al todo, éste se subordina a aquel. La distinción en niveles diferenciados ordena las definiciones: la política es la inteligencia del Estado personificado, la estrategia es la combinación de las batallas, y la táctica es la conducción de la fuerza militar en la batalla.

\section{ACTUALIDAD y APERTURAS}

El pasaje del movimiento de ascenso al movimiento de descenso describe una onda en la que el duelo de voluntades es progresivamente dominado por el entendimiento político, que introduce la búsqueda de proporción entre la magnitud del esfuerzo y la calidad del objetivo.

La inteligencia del Estado personificado decide concretamente sobre la proporción entre los esfuerzos y los fines. No es, pues, un cálculo abstracto, sino un concepto de lo concreto, en la medida que está ensamblado en una situación concreta. La crítica de Clausewitz apunta al dogmatismo, a la universalización de una particularidad, y a la elevación al plano estratégico de una situación táctica.

El pensamiento dialéctico de Clausewitz se anuda con la constatación de la "guerra como camaleón»: preserva su identidad, pero cambia de aspecto. La metamorfosis de la guerra implica dialéctica, no es movimiento caótico sino estructuralmente determinado por la primacía de uno u otro de los componentes de la trinidad. El significado de Clausewitz trasciende la universalización conceptual de las guerras napoleónicas: Vom Kriege esconde un tratado de teoría política contemporánea entre los pliegues de un manual de operaciones vetusto.

Como las partes remiten al todo, Vom Kriege es una obra orgánica ${ }^{5}$, aunque la redacción definitiva no fue realizada, quedando pendiente la tarea de interpretarla y recrearla tomando en consideración la primacía de la política y las dos especies de guerra. La vigencia de Clausewitz no es dogmática, sino teórico política y está sujeta a la investigación de la historicidad de la guerra, de su metamorfosis en función de las

En el Athenäums-Fragment $\mathrm{N}^{\circ} 116 \mathrm{el}$ grupo de los Schlegel, al buscar una adecuada forma literaria, no conocía ninguna más próxima a sus ambiciones que abarcaban el todo, que «aquella novela que había logrado una perfección impresionante en el Wilhelm Meister de Goethe». 
realidades políticas y las totalidades histórico-concretas, «sociales».

La distinción entre paz y guerra por la naturaleza del medio resuelve una confusión común en nuestro tiempo. $\mathrm{Ni}$ simbólica ni social, la guerra es violencia organizada. La paz, es ausencia de violencia organizada. De este modo, la distinción específica de la guerra como choque de totalidades, intenciones hostiles y actos hostiles, se opone avant la lettre a la extensión de la violencia al plano simbólico, y a la inversión de la fórmula. La extensión del concepto de guerra a situaciones en las que no chocan fuerzas militares manifiesta en el plano retórico la intensidad de las tensiones. Una concepción así carece de distinción pues difumina el contorno, el contenido concreto y la consistencia comprensiva del concepto de guerra. La vigencia de Clausewitz radica en la continuidad de su modalidad analítica. La distinción paz y guerra por la naturaleza del medio es determinante para construir una teoría de la situación político estratégica.

En esta senda, Iberoamérica es espacio de intenciones hostiles. Con alguna salvedad, el conflicto entre las fuerzas del socialismo siglo XXI y quienes lo enfrentan no constituye una guerra, pues no está involucrado el acto hostil con empleo de instrumento militar. Una contradicción político-ideológica de alta intensidad acompañada por una carrera armamentística a escala regional es una situación novedosa, pero no es una guerra. La paz actual se debe más a la ambigüedad de la ideología neobolivariana, y a la debilidad y las contradicciones del bando opuesto, que a la ausencia de sentimientos hostiles. Los fines políticos del socialismo siglo XXI sobrepasan el marco del régimen democrático moderno mediante transformaciones constitucionales en sentido socialista. Plebiscito a plebiscito, se procede al vaciamiento del constitucionalismo liberal iberoamericano. La alta intensidad de los sentimientos y las intenciones involucradas hacen poco probable el encauzamiento permanente de las fuerzas en la competencia electoral, incluso bajo modalidad restrictiva. El modelo abstracto del duelo y el ascenso a los extremos acaso puede dejar lugar a la guerra real. En el caso del principal promotor del socialismo siglo XXI, el presidente venezolano Hugo Chávez, la aplicación de una diplomacia expansiva y revolucionaria configura una situación de heterogeneidad ideológica en un subsistema pluripolar (Aron, 1963: 163-190) ${ }^{6}$. Las tensiones actuales tienen final abierto: revolución armada, golpe de Estado, moderación general o guerra civil e interestatal, la gama de las posibilidades es amplia. Es difícil prever el futuro, pero es altamente probable que el estallido no sea una guerra de liberación nacional, como anuncia la retórica neobolivarista. Una guerra de liberación nacional enfrenta un ejército

$6 \quad$ Una guerra en un tercer país con intervención de Venezuela es un peligro ya sorteado en algunas oportunidades. En última instancia, Chávez parece que busca su guerra internacional y ningún lector de Clausewitz debería asombrarse si la consigue. 
de liberación contra fuerzas de ocupación extranjeras y tiene como objetivo la descolonización y la independencia nacional. Las guerras de Indochina y de Argelia contra el ejército francés de ocupación ofrecen un arquetipo en ese sentido: las doctrinas de la contraguerrilla y la contrainsurgencia cometen el error dogmático de generalizar al plano político estratégico una modalidad táctica. Se inscriben en la saga de von Bülow. Ni los mejores métodos de combate guerrillero, ni las técnicas más insidiosas de acción psicológica y propaganda convencieron a las poblaciones de los países coloniales de una supuesta identidad nacional compartida con la metrópoli. En plena época de los Estados nacionales, la fuerza de la descolonización se origina en un sentido político que la fuerza táctica del ocupante no puedo erradicar.

La guerra revolucionaria, en cambio, enfrenta bandos integrantes de un mismo Estado. Es una guerra en el interior de una misma unidad política, que puede fragmentarse excepcionalmente, pero sin dejar de remitir a un orden normal de funcionamiento de la unidad política, que cada bando reivindica para sí. Como en el caso de China e Indochina, la guerra de liberación nacional puede transformarse en guerra revolucionaria cuando participa un ejército político de ideología comunista.

En Vom Kriege el modo de conclusión de la guerra determina la especie. El historiador de la guerra Hans Delbrük (1920: 465) sostiene que la distinción de las especies de guerra implica dos tipos de estrategia, una de aniquilamiento, otra de desgaste. Sin embargo, puede establecerse una nueva polaridad entre la especie de guerra y el tipo de estrategia, pues la modalidad estratégica tiene más flexibilidad que la especie de guerra.

Una guerra puede ser de la primera especie y concluir en el aniquilamiento de uno de los bandos, mediante el choque de estrategias de desgaste. La descomposición política de un gobierno favorece a una guerra revolucionaria que acumula victorias tácticas sin involucrar una estrategia de aniquilamiento, ni desembocar en una gran batalla de aniquilamiento. La estrategia de desgaste puede forzar el colapso del bando enemigo, para aniquilarlo luego de rendido. Es decir, después que concluya la guerra, pues como afirma Clausewitz no puede entenderse como guerra el aniquilamiento físico de una masa inerte.

Las guerras revolucionarias victoriosas en China, Cuba y Nicaragua desplegaron estrategias de desgaste en guerras de aniquilamiento por naturaleza, en guerras de la primera especie. De modo opuesto, puede darse el caso de una segunda especie de guerra- la que concluye mediante paz negociada y observación armada-combinada con una estrategia de aniquilamiento. En la guerra de las Malvinas, la definición argentina del Teatro de Operaciones del Atlántico Sur y la definición británica de la Zona Marítima de Exclusión limitaron el alcance de la guerra. Sin embargo, ambos bandos emplearon 
una estrategia de aniquilamiento y no rehuyeron a las batallas clásicas (de Goose Green a Puerto Argentino).

Puede darse el caso de que se enfrenten dos estrategias de desgaste, guerrilla y contraguerrilla, terrorismo y contraterrorismo. Y también una estrategia de aniquilamiento contra otra de desgaste. La flexibilidad de la dialéctica clausewitziana abre el horizonte a nuevas polaridades y combinaciones.

La imaginación estratégica y los conocimientos tácticos que dieron lugar a la literatura de la lucha de guerrillas, y su simétrica lucha contrainsurgente y contraguerrillera, están encapsulados en el límite de lo político. Es la cuestión decisiva del fin político lo que debe resolver el bando que aspire al éxito. La dialéctica de la guerra es la expresión militar de un enfrentamiento entre fines políticos opuestos. De la naturaleza política de la guerra se infiere la primacía del fin político sobre el objetivo militar. La persuasión sobre el fin encuadra al objetivo. De la calidad, pertinencia y atractivo de los fines se desprende buena parte de la posibilidad de concluir con éxito la guerra. Si la guerra se limita a reivindicaciones territoriales el objetivo militar es idéntico al fin político. Si el fin político se inscribe en el balance de poder, el objetivo militar es un subconjunto dentro del fin político. La distinción entre ambos planos es fundamental en una guerra revolucionaria o contrainsurgente, de liberación nacional o de dominación imperial. Con frecuencia, las acciones de guerra contrainsurgente y contrarre- volucionaria del campo occidental no proveyeron fines políticos atractivos para las sociedades civiles, quizá por involucrarse con círculos recalcitrantes. En ciertos casos, la elevación de la táctica al plano político-estratégico empalma con la voluntad de preservar el estado de cosas. Los dirigentes de las revoluciones victoriosas no cometieron el error de sus enemigos.

El desconocimiento de la supremacía del fin político, y su incardinación con los niveles especiales táctico (conducción de las fuerzas armadas en la batalla), y estratégico (empleo y enlace de las batallas en función del fin de la guerra); la exaltación del componente táctico a la categoría de nivel dominante, en suma, la saga de Bülow y Jomini, se desplegó también entre las fuerzas revolucionarias. La interpretación de Ernesto Guevara sobre la Revolución cubana es un ejemplo de error dogmático: la teoría de la creación de condiciones subjetivas revolucionarias por el foco guerrillero también supone la elevación de la táctica al plano políticoestratégico. El Che Guevara teorizó sobre el desarrollo revolucionario desde el foco guerrillero inicial hasta la toma del poder y pagó con su vida ese error dogmático. Lenin y Mao Tse Tung en cambio, sostuvieron siempre la primacía de la conducción política sobre la conducción militar. En los comentarios a Vom Kriege, conocidos como Tetra$d k a$, Lenin afirma que «el carácter del fin político tiene una influencia decisiva sobre el fin de la guerra. Guerra = parte de un todo; Ese todo = la política» 
(1979: 81). En continuidad con esa línea, Mao Tse Tung pregona la supremacía del Partido Comunista sobre el Ejército, pues emana del carácter político de la guerra revolucionaria, y sostiene que el trabajo político domina a la acción militar. Paso a paso, Mao extrajo capacidades allí donde había intenciones. No fue un militar profesional, pero desarrolló un desempeño militar victorioso y una capacidad de comprensión del pensamiento de Clausewitz que sus enemigos no siempre tuvieron. Por ello Aron sostuvo que «en términos abstractos, Clausewitz, Marx, Lenin y Mao concuerdan en enseñarnos que las guerras sólo adquieren sentido a la luz de la política, en los dos sentidos de esta palabra: la coyuntura de donde surge la guerra, la intención de los combatientes» (1989: 144).

La crítica leninista a la tesis de la política como inteligencia del Estado personificado, y la subsiguiente afirmación de la lucha de clases de la que el Estado es un instrumento, no constituyen razón suficiente para refutar la tesis de Clausewitz.

Por un lado, Clausewitz vivió en la época de las guerras napoleónicas y de la restauración de la monarquía: la concentración del poder en la persona de Bonaparte y de los monarcas era evidente, al punto que lo realmente difícil consistía en distinguir la presencia de las fuerzas históricas en la trama de las decisiones. En el mundo occidental actual la monarquía absoluta es un dato del pasado. Sin embargo, en las guerras reales las naciones y los ejércitos respondieron más o menos homogéneamente.

En relación con a las armas atómicas que sellan la condición de la guerra fría, la decisión final estuvo siempre en los jefes de Estado. "La política del área socialista o del área atlántica se parece más a una inteligencia del Estado personificado en la medida en que una sola persona tiene el mando de una sola fuerza nuclear» (Aron, 1989:174).

Por otra parte, la concepción marxista de la lucha de clases se enfrentó a la evidencia empírica de la heterogeneidad ideológica y política de las «clases sociales». Ni la retórica leninista del partido como «representante» de la clase obrera, ni las torsiones pseudohegelianas que distinguen clase en sí de clase para síalcanzan a cubrir la brecha: no se enfrentan tan claramente las clases contra las clases como se enfrentan los fines contra los fines y los hombres contra los hombres. En éste aspecto, Clausewitz está por encima de la teoría marxista.

\section{A MODO DE CONCLUSIÓN}

El pensamiento de Clausewitz ha sido reinterpretado generación tras generación de modos diversos e incluso opuestos. Mediante formas siempre renovadas, Vom Kriege ha estado presente en grandes debates de la política, como teoría y práctica. El más grande de sus intérpretes afirmó que «el orden político es inseparable de las hostilidades [...] por debajo de un Estado planeta- 
rio, los grupos no vivirían en paz si, como las conciencias según Hegel, cada uno quiere la muerte del otro» (Aron, 1973:877). Clausewitz sostiene una idea de la política que prepara la definición schmittiana de lo político mediante la distinción amigo-enemigo, pues restablece el estado de naturaleza como constitutivo de la teoría de lo político, y como patentización de un estrato insuperable de la realidad humana. Lo político es inseparable de las intenciones hostiles y el estado de naturaleza es la condición fundamental de las contradicciones en el plano de los fines.

El encuentro con el pensamiento de Clausewitz nos devuelve la posibilidad de la política como vida seria. Clausewitz afirma que "la guerra es un medio serio para un fin serio", oponiéndose al mundo burgués, a la vida como consumo y goce estético, a la ironía romántica, a la vaga conciencia de los fines de las guerras de maniobra previas a la Revolución, y a la mera violencia desenfrenada. La posibilidad de participar del enfrentamiento armado en razón de un fin político reafirma un modo de vida serio, en el que las posibilidades individuales se conectan con los fines colectivos en relación al caso límite. Para un pensamiento así, lo político implica reflexión sobre los fines y los medios, y voluntad de persistir a riesgo de encontrar una muerte violenta. En este punto, Clausewitz sobrepasa la sistemática liberal y presenta una posibilidad de la vida por encima del bourgeois.

La razón del fin (Zweck) domina al objetivo (Ziel). El jefe político se impo- ne al jefe militar y este a la masa de los soldados, por la razón o la fuerza. Por cierto, la guerra es un drama sangriento y terrible, en el que la enajenación de los combatientes se cruza con el entusiasmo, y las pasiones se disciplinan con métodos diversos. Así y todo, para un pensamiento consecuente inspirado en Clausewitz, la visión de la sociedad comunista en la que el hombre "pueda dedicarse hoy a esto y mañana a aquello [...] por la mañana cazar, por la tarde pescar y por la noche apacentar el ganado, y después de comer, si place, dedicarse a criticar, sin necesidad de ser exclusivamente cazador, pescador, pastor o crítico» (Marx, Engels, 1982: 33) aparece como la consumación total del bourgeois. Lenin pudo reprochar a Clausewitz haber soslayado la lucha de clases, pero vista desde Clausewitz la utopía comunista no es más que una perfecta sociedad de snobs.

El estado de naturaleza entre las unidades estatales corresponde al plano de lo absoluto, mediatizado y superado en el nivel histórico-concreto, que aparece como reino de fines contrapuestos. ¿Es compatible la tesis del estado de naturaleza en las relaciones interestatales con la de «medio serio para un fin serio»? Desde la perspectiva del sujeto, la seriedad de los fines se manifiesta en el choque con otros fines, en la guerra entre los Estados. Puede haber estado de naturaleza y primacía de fines si los fines se contraponen, y el enfrentamiento no se evite mediante ley común ni juez superior. Por cierto, el estado de naturaleza ya no es mero estado de 
inocencia animal. En tanto la seriedad los conmina a la guerra, el estado de naturaleza está conservado como negado (Aufhebung) en la contraposición de los fines. La disidencia con la visión liberal comercial de Montesquieu y Kant, y con la pesadilla marxista, es superior a las coincidencias aparentes.

La gravedad de una teoría de la política que lleva en sí la posibilidad de la guerra no envuelve un objetivo criminal, ni es un discurso productor de profecía autocumplidora. Ni la brutalidad ni la delicadeza en particular son parte de la teoría, de igual forma que la analítica del modo de producción prescinde de la conducta directa del capitalista individual. Así se trate de un caso o de la mayoría, la crítica teórica se concentra en la sustancia, no en los accidentes. Ni la filantropía ni la crueldad cambian el modo de producción, ni hacen menos guerra a la guerra.

Por cierto, la guerra no requiere crueldad, ni la política beligerancia. Alcanza con un fin que se contraponga a otro fin y un grupo de hombres a otro grupo de hombres, para que la seriedad de la vida se manifieste. Autores más a tono con nuestra época, con menos dificultades de interpretación, difícilmente nos enseñarían tanto.

\section{BibliografíA}

Aesch, Alexander (1947), El romanticismo $y$ las ciencias naturales, Buenos Aires, Espasa-Calpe.

Aron, Raymond, (1963), Paz y Guerra entre las Naciones, Madrid, Revista de Occidente.
-. (1989), Pensar la Guerra, Clausewitz, Buenos Aires, Instituto de Publicaciones Navales.

- (2009), Sobre Clausewitz, Buenos Aires, Nueva Visión, 2009.

Brodie, Bernard (1973), War and Politics, Nueva York, The Macmillan Company. Hay version en español traducida por Eduardo L. Suárez (1978), Guerra y Política, México, Fondo de Cultura Económica. Clausewitz, Carl, (1832), Vom Kriege, Bonn, Dümmlers Verlag.

- - (1960), De la Guerra, Buenos Aires, Ediciones Mar Océano, traducida por R.W. de Setaro.

Del Arenal, Celestino (1994), Introducción a las Relaciones Internacionales, Madrid, Tecnos, pp.19-37.

Delbrück, Hans (1920), Die Geschichte der Kriegskunst im Rabmen der politischen Geschichte, Berlín, Dümmler.

Fernández Vega, José (2005), Las guerras de la política. Clausewitz de Maquiavelo a Perón, Buenos Aires, Edhasa.

Goethe, Johann Wolfgang, (1999), Elegías romanas, edición bilingüe de Adan Novascics, España, Círculo de Lectores.

- (1947), Die Schriften zur Naturwissenschaft, Vollständige mit Erläunterunger versehene Ausgabe herausgegeben im Auftrage der deutschen Akadenie der Naturforscher Leopoldina, R. Matthaei, Böhlau, Weimar, Troll und Lothar.

- (1997), Teoría de la naturaleza, Madrid, Tecnos.

-. (2002), Goethe y la Ciencia, Madrid, Biblioteca de Ensayo Siruela.

Heine, Enrique (1943), Que es Alemania, Buenos Aires, Editorial Americalee, pp.153-280.

Holsti, Kalevi (1996), The State, War, and the State of War, Nueva York, Cambridge, Routledge.

Hoffman, Stanley (1991), Jano y Minerva: Ensayos sobre la Guerra y la Paz, Buenos Aires, Grupo Editor Latinoamericano.

Howard, Michael (1983), La Guerra en la Historia europea, México, Fondo de Cultura Económica.

Kant, Inmanuel,(2001), La paz Perpetua, Madrid, Biblioteca Nueva. 
Kondylis, Panajotis (1988), Theorie des Krieges. Clausewitz, Marx, Engels, Lenin, Stuttgart, Klett- Cotta.

Kissinger, Henry(1974), American Foreign Policy, The Brookings Institution.

Lenin, Vladimir (1979), «La obra de Clausewitz De la Guerra: extractos y acotaciones»; en Clausewitz en el pensamiento marxista, México, Cuadernos de Pasado y Presente, pp. 47-98.

Luttwak, Edward (1992), Estrategia: la lógica de la guerra y la paz, Buenos Aires, Instituto de Publicaciones Navales.

Marx, Carlos y Engels, Federico (1982), La Ideología Alemana, La Habana, Pueblo y Educación, p.33.

Mead Earle, Edward (1968), Creadores de la estrategia moderna, Buenos Aires, Círculo Militar, Buenos Aires.
Meinecke, Friedrich (1982), El historicismo y su génesis, México, Fondo de Cultura Económica.

Paret, Peter (2007), Clausewitz and the State: The man, His Theories and His Times, Princeton, University Press.

Rapoport, Anatol, (1992), Clausewitz: filósofo de la guerra y la política, Buenos Aires, Leviatán.

Schmitt, Carl, (2000), Romanticismo Político, Argentina,Universidad Nacional de Quilmes Ediciones.

. (Sine Data), Clausewitz como pensador político o el honor de Prusia, Buenos Aires, Struhart \& Cía..

Staël, Madame von (1947), Alemania, Buenos Aires, Colección Austral, pp. 58-62, 66-70, 107-121.

Van Creveld, Martin (1985), Command in war, Massachusetts, Harvard University Press. 